\title{
SOME ASPECTS ON ADJUSTING THEORY WITH PRACTICE USING AN INTELLIGENT E-LEARNING SYSTEM
}

\author{
Lecturer PhD Nicolae Mărginean, “Bogdan-Vodă” University \\ ofCluj-Napoca, e-mail: nicolae1976@yahoo.com \\ Professor PhD Dan Racovițan, "Bogdan-Vodă” University \\ ofCluj-Napoca, e-mail: ubv@ubv.ro
}

\begin{abstract}
The goal of this article is to present an architecture of a system that tries to prepare the students from specialization "Computer science in Economy" for the labor market, through a integrated, interactive and intelligent system, gained through a proactive collaboration between the university and the business environment, in order to adjust the theoretical knowledge (transmitted in university) to the practice (specific to labor market). Two concepts are essentials: expert system and E-Learning.
\end{abstract}

Keywords: expert system, e-learning, theory, practice, production rules

JEL Codes: $M 15$

\section{Introduction}

The goal of this article is to present an architecture of a system that tries to prepare the students from specialization "Computer science in Economy" for the labor market, through a integrated, interactive and intelligent system, gained through a proactive collaboration between the university and the business environment, in order to adjust the theoretical knowledge (transmitted in university) to the practice (specific to labor market).

Such a system promotes knowledge-based management in an organization by introducing expert systems that capture and store specific knowledge of the departments from an organization. Knowledge is one of the essential resources of an organization and their availability for the staff means more competitiveness and labor productivity. In addition, for future employees (school leavers), electronically availability of expertise specific to a job facilitate adaptation in the new position of human labor.

Also, the proposed system, by the E-Learning component inserted, presents a series of advantages for the education of a student as they are often presented in literature. Online education, occurred as a result of the development of information and communication technologies, is a further opportunity offered to those who want to build on a continuous basis. This does not preclude learning classical education but it completes it, adding virtual educational resources to the classical real educational resources.

Very few of the graduates of institutions of higher education know what competencies to be gained from years of finalizing the study. Through the proposed system, a student, not only will be familiar with the demands of practice, but more are presented in both synthetic and analytical knowledge required, as resulting from the labor market. 


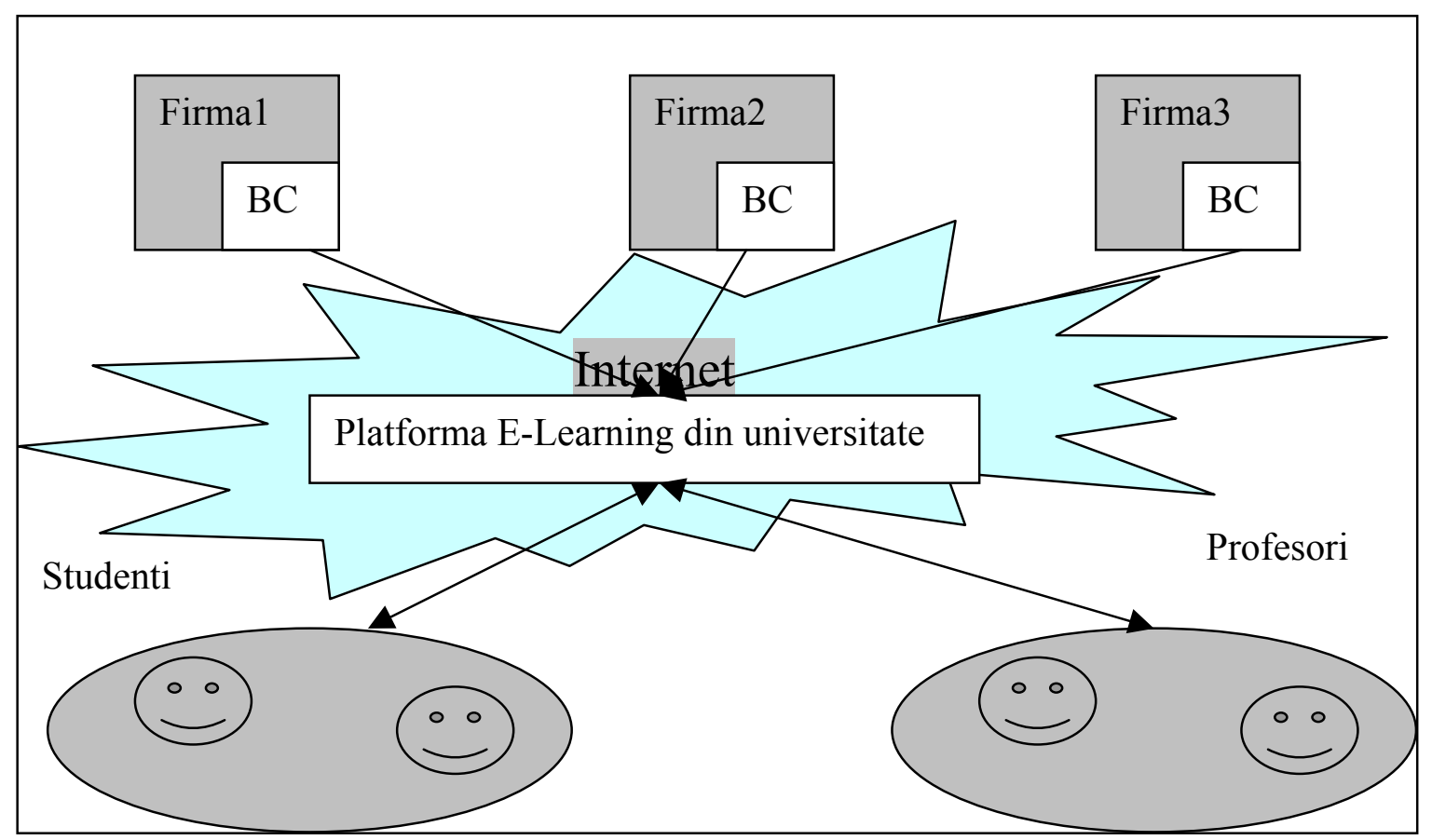

Fig. No. 1. The proposed architecture of the intelligent E-learning system

\section{Building the system}

To study the desirability of introducing such a system will take into account several criteria (essential criteria, desirable criteria), among others being considered and issued by [Puppe, 1993] to introduce such a system and ARACIS standards on distance education. The feasibility study will take into consideration the following directions: economic and financial feasibility, technical feasibility and the impact of introducing such a system. To obtain relevant results, to identify appropriate tools to solve the problem, will appeal to more sources of documentation, starting with the study of specialty literature, continuing with legislation and ending with studies in the field existing in Internet.

The starting point in establishing the competencies and knowledge specific to a Bachelor of "Computer Science applied in Economics" is represented by the occupational standard defined by CNFPA for software engineer. Needs of the target group can be traced in the analytical disciplines sustained in universities as well as in occupation standard of CNFPA having COR code 213905 specific to software engineer.

Thus, any graduated student must:

- communicate at work,

- be team working,

- coordinate a team of specialists ,

- be able to organized activities,

- know the main mechanisms and economic departments of an organization,

- be an IT \& C project manager,

- maintain the functionality of an IT \& C solutions,

- be able to monitor existing systems in an organization,

- develop new systems,

- be able to teach users of existing systems in an organization. 
It will be organized a workshop with invited guests from the business environment in order to set a clear profile of graduates from "Computer Science in Economics", and for a clear identification of the new system requirements had in mind.

Visits made to companies in Cluj county will assume the application of established methods of acquisition of knowledge (interview, observation during work, brainstorming method, etc.) in order to build the future knowledge base. Acquisition of knowledge is primarily lead by the reminded existing occupational standard of software engineer. After the visits, it will be maked several meetings in order to synthesize knowledge acquired in the labor market. For representation of knowledge it will be used the technology of production rules.

To prevent a supra dimensioning knowledge base, as a result of the continuous addition of new rules, to prevent the existence of conflicting rules, it requires the existence of procedures to optimize them, to be launched regularly by each party holds in a dynamic knowledge base. It will be used intelligent tools based on genetic algorithms to optimize knowledge.

Shortly, we propose the next pseudocode for the reminded procedure:

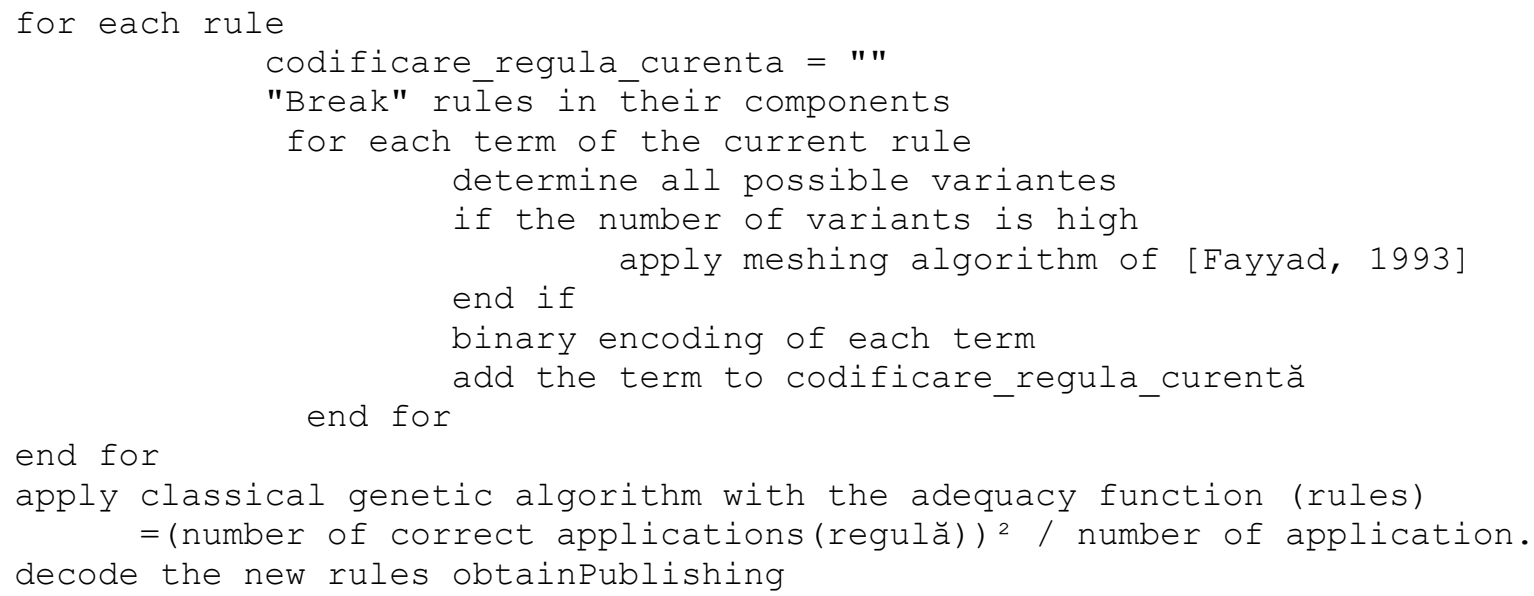

To develop the expert system, as interface for the knowledge base built before, it will call the prototyping method, which assumes in essence, building a prototype initially to be readjusted until requirements are met. As a programming language it will be used Visual Prolog. Prototypes will be validated by specialist of firms involved and technical adjustments will be made by the project team members. Finally, it will be implementing the expert system in the companies that like the idea of the proposed project.

E-Learning platform will be developed using the open-source package Moodle, making available all services offered by this component as well as teaching, communication, assessment. Integrating E-Learning platform existing in university with expert systems available to beneficiary companies will be achieved by building a Web interface for the expert system and call it from the E-Learning platform.

To assess students, tests will be prepared in accordance with the guidelines drawn in an earlier workshop and its will be available in the platform of E-Learning. Evaluation of students will be achieved through compulsory examination organized by the university at the end of the semester and by organizing a special contest, in which companies interested in cooptation of graduates of "Computer Science in Economics" will establish the topics that will determine the contest and will evaluate the students. Also, every student will submit a draft summary to the company where he conducted business, in order to be evaluatPublishing

All results will be included in online courses that teachers have proposed to achieve and we believe it will lead to widely disseminate the results of the presented system. 


\section{Conclusions}

By building the presented system, for all students from specialization "Computer Science in Economy", it is facilitating the transition from school to life by the acquisition of competency in accordance with the labor market. The system will contribute to improving skills of students and in dissemination of knowledge to their work or business partners with whom they come into contact.

Knowledge Base, in computerized format on the knowledge and skills of a Bachelor of "Computer Science in Economics" is one of the great achievements of the presented system. This promotes directly knowledge management with its benefits.

Making an interactive learning platform, used to deepen practical knowledge necessary labor market, is another notable achievement of the project being. Obtained online courses are designed in accordance with the requirements of the labor market, deepening the theory of their practice in the labor market.

A very important achievement of the presented system is the close cooperation between the university and the specific labor market by using an integrated IT system, in which communication is done via the Internet. Also, another achievement is the design of a training system of graduates from "Computer Science in Economics", validated by the labor market in collaboration with the university, in order to increase employers' confidence in the ability of new graduates, and consequently, opportunities for employment of graduates .

The idea incorporated in the system can be used in updating and validating occupational specific standard for software engineer, by adapting it to new market demands.

\section{References:}

1. Andone Ioan, Tugui Alexandru, "Sisteme inteligente în management, contabilitate, finante, bănci şi marketing", Publishing Economică, Bucureşti, 1999

2. Andone I, Tugui A, "Dezvoltarea sistemelor inteligente în economie", Economică Publishing, Bucuresti, 2001

3. Berceanu O, Bacanu D, "Minighid de managementul proiectului", POSDRU, 2006

4. Brut M, "Instrumente pentru E-Learning", Publishing Polirom, Iaşi, 2006

5. Buraga S, "Proiectarea site-urilor WEB", Publishing Polirom, Iasi, 2005

6. Fayyad UM, Irani, "Multi-interval discretization of continuous-valued attributes for clasification learning", 1993

7. Marginean N, Vultur S, Marincas D, "Introducere in Inteligenta Artificiala", Publishing Risoprint, Cluj-Napoca, 2007

8. Marginean Nicolae, "Sisteme inteligente de asistare a deciiilor", Publishing Risoprint, ClujNapoca, 2006

9. Oprean D, Racovitan D, Oprean V, Rusu L, "Managementul afacerilor pe Internet", Publishing Risoprint, Cluj-Napoca, 2007

10. Puppe F., "Systematic Introduction to Expert Systems - Knowledge representation and Problem-Solving", Springer-Verlag, Berlin, 1993

11. www.cnfpa.ro

12. www.moodle.org 